\title{
Clinical Trial Data Privacy Agreement
}

National Cancer Institute

\section{Source}

National Cancer Institute. Clinical Trial Data Privacy Agreement. NCI Thesaurus. Code C115474.

A legally binding document that contains the provisions governing the use of, and access to, any and all data obtained from a particular clinical trial. 